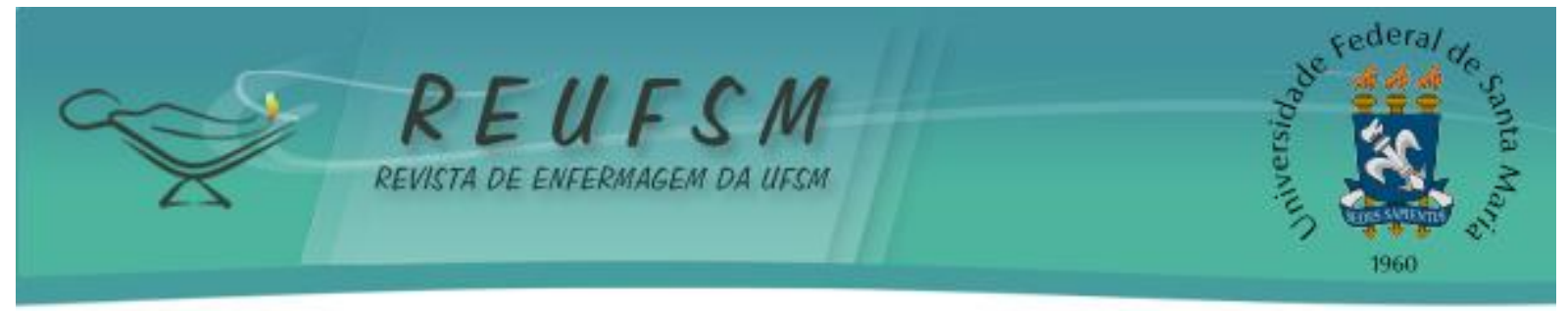

ARTIGO ORIGINAL

\title{
ESTRATÉGIA DE SAÚDE DA FAMÍLIA E O SISTEMA DE REFERÊNCIA E DE CONTRA- REFERÊNCIA: UM DESAFIO A SER ENFRENTADO
}

\section{STRATEGY OF HEALTH AND FAMILY REFERENCE SYTEM: THE CHALLENGE TO BE FACED \\ ESTRATEGIA PARA LA SALUD DE LA FAMILIA Y EL SISTEMA DE REFERENCIA: UN DESAFIO A SE ENFRENTADO}

Leticia Martins Machado ${ }^{1}$

Juliana Silveira Colomé

Carmem Lúcia Colomé Beck ${ }^{3}$

RESUMO: Estudo qualitativo que objetivou analisar a percepção de profissionais da Estratégia de Saúde da Família acerca do sistema de referência e contra-referência de um município do interior do estado do Rio Grande do Sul. Participaram do estudo profissionais integrantes de duas equipes de saúde, totalizando nove participantes. A coleta de dados foi feita por meio de entrevista semi-estruturada e os dados submetidos à análise de conteúdo temática. Ao analisar os dados, concluiu-se que existem lacunas que restringem as ações do sistema de referência e contra-referência, o qual embora represente uma ferramenta para o desenvolvimento de serviços de saúde pautados na integralidade, encontra dificuldades para sua efetivação na realidade investigada. Considera-se a necessidade de uma reorganização dos serviços de saúde, uma vez que os fundamentos do Sistema Único de Saúde parecem ainda não terem sido incorporados na organização do sistema e, consequentemente, no fazer dos profissionais que atuam neste contexto.

Descritores: Enfermagem; Saúde da família; Saúde pública; Sistema Único de Saúde.

ABSTRACT: The aim of this qualitative study was to analyze the perception of professionals from the Family Health Strategy concerning the system of reference and counter-reference in a country town in Rio Grande do Sul. The participants were professionals from two health teams, there were a total of nine participants. The data collection was done through semi-structured interview and then the data was subjected to thematic content analyzes. By analyzing the data, it was concluded that there are gaps restricting the actions of the reference and counter-reference system, which although represents a tool for the development of health services listed integrally, it faces difficulties in its implementation in the investigated reality. It is considered the necessity of a reorganization in health services, since the fundamentals of the Single Health System does not seem to have been incorporated in the organization of the system, hence on the jobs of the professionals who work in this context.

Descriptors: Nursing; Family health; Public health; Single Health System.

RESUMEN: Este estudio cualitativo tuvo como objetivo analizar la percepción de los profesionales de la Estrategia de Salud Familiar en el sistema de referencia y una

\footnotetext{
${ }^{1}$ Enfermeira graduada pelo Centro Universitário Franciscano-UNIFRA. Mestranda do Programa de Pós-Graduação em Enfermagem-Mestrado em Enfermagem, na Universidade Federal de Santa Maria- UFSM. lehmachado@yahoo.com.br

2 Docente do Centro Universitário Franciscano-UNIFRA. Mestre em Enfermagem pela Universidade Federal do Rio Grande do Sul-UFRGS. Membro do GEPESE-Grupo de Estudos e Pesquisa em Empreendedorismo Social da Enfermagem e Saúde. julianacolome@yahoo.com.br

3 Docente do Departamento de Enfermagem da Universidade Federal de Santa Maria-UFSM. Doutora em Enfermagem. Membro do Grupo de Pesquisa Trabalho, Saúde, Educação e Enfermagem-UFSM. carmembeck@gmail.com
} 


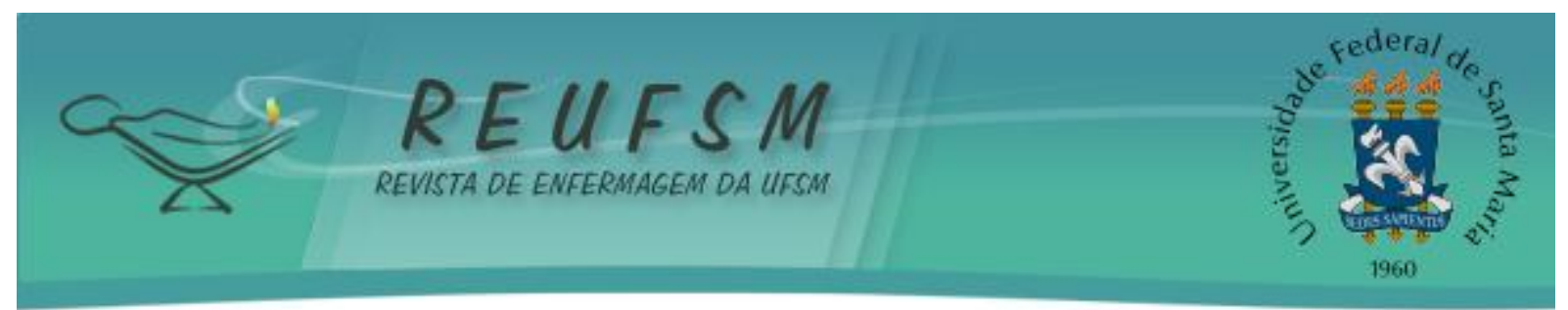

referencia cruzada a un municipio en el estado de Rio Grande do Sul. Los participantes eran profesionales que trabajan en dos equipos de salud, por un total de nueve los participantes. La recolección de datos se realiza a través de entrevista semi-estructurada y los datos sometidos a análisis de contenido temático. Al analizar los datos, llegamos a la conclusión de que existen lagunas que limitan las acciones del sistema de referencia y la referencia cruzada, que a pesar de que representa una herramienta para el desarrollo de servicios de salud guiados por la totalidad, se encuentra con dificultades para su aplicación en la realidad investigada. Se considera la necesidad de una reorganización de los servicios de salud, ya que los fundamentos del Sistema Único de Salud no parece que se han incorporado a la organización del sistema y por lo tanto hacer que los profesionales que trabajan en este contexto.

Descriptores: Enfermería; Salud de la familia; Salud pública; Sistema Único de Salud.

\section{INTRODUÇÃO}

A gestão pública dos serviços de saúde, na perspectiva do Sistema Único de Saúde (SUS), tem sido alvo de reflexões e novas proposições. Neste sentido, a visão atual de gestão pública enfatiza as possibilidades de decisões descentralizadas, produto da construção e consolidação do SUS, a qual vem sendo viabilizada pelos seus princípios fundamentais de Universalidade, Equidade e Integralidade. ${ }^{1}$

$\mathrm{Na}$ perspectiva de reorientação do atual modelo assistencial, preconiza-se que a Estratégia de Saúde da Família (ESF), por meio dos pressupostos da Atenção Básica, seja a "porta de entrada", ou seja, o primeiro contato dos usuários com os serviços de saúde, além de organizar a referência e contra-referência. Neste contexto, as ações vão além dos cuidados primários, orientando o fluxo dos usuários pelos diferentes níveis de atenção à saúde.

Em muitas situações, percebe-se que a preocupação das Equipes de Saúde da Família, em prestar atenção integral aos usuários, é dificultada pela ausência de uma rede regionalizada de referência e contra-referência de serviços assistenciais. Assim, a partir do instante em que a continuidade do cuidado é rompida, há a predominância e o fortalecimento do modelo clássico de assistência em saúde, o qual se sustenta pelo modelo biomédico de consultas, que busca, essencialmente, solução para os sinais e sintomas apresentados pelo indivíduo, em detrimento de uma atenção integral. ${ }^{2}$

A história das políticas de saúde do Brasil é marcada por mudanças, as quais acompanham as transformações econômicas, socioculturais e políticas da sociedade brasileira. A essência desta trajetória é marcada pela ênfase na assistência médica individual, assistencialista e especializada, preconizando a geração do lucro em detrimento da saúde pública, o que, consequentemente, gerou sucateamento e precarização de seus serviços. ${ }^{3}$

Neste contexto de crise do setor saúde, emergem discussões acerca da necessidade de reformas nas políticas de saúde e surge o movimento conhecido como Reforma Sanitária. As idéias e discussões emergentes no contexto deste movimento tiveram expressão na $8^{\text {a }}$ Conferência Nacional de Saúde (CNS), que ampliou a concepção de saúde, entendida como resultante das condições de vida das pessoas, possuindo, dessa forma, alguns fatores determinantes como alimentação, moradia, meio ambiente, ocupação, renda e oportunidade de acesso a serviços de saúde, dentre outros. ${ }^{4}$

Nesta perspectiva, a Constituição Federal, aprovada em 1988, resgatou as propostas da $8^{a}$ CNS e criou o SUS, definindo em seu Artigo 196 um conceito de saúde que considerou a saúde como direito de todos e dever do estado. ${ }^{5}$ Em 1990, o SUS foi 


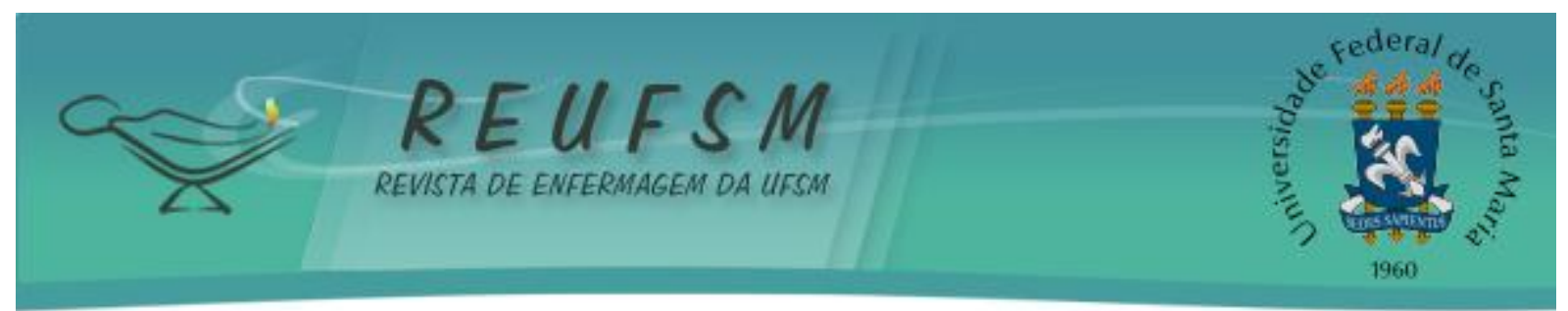

regulamentado pelas Leis Orgânicas da Saúde $8080 / 90$ e $8142 / 90$ ", nas quais se estabelecem seus princípios e diretrizes.

Destaca-se no âmbito do SUS, a Estratégia de Saúde da Família, a qual traz o princípio da integralidade como um de seus principais eixos estruturantes. Esta Estratégia desponta no contexto da saúde brasileira como uma forma de reorganizar a Atenção Básica, tendo como principal desafio promover a reorientação das práticas e ações de saúde de forma integral e contínua. ${ }^{7}$

Enfatiza-se ainda, a multiplicidade de redes que se formam nos serviços de saúde, as quais operam por meio de conexões entre si, em diversas direções e sentidos, construindo linhas de produção do cuidado que têm o trabalho vivo como dispositivo de formação de fluxos-conectivos, os quais assumem características de multiplicidade e heterogeneidade, sendo capazes de funcionar em alto grau de criatividade. ${ }^{8}$

O trabalho em saúde se organiza a partir de encontros entre trabalhadores, e desses, com os usuários. São fluxos políticos, comunicacionais, subjetivos que estão permanentemente entre os sujeitos, formando uma intricada rede de relações que dá condições para desenvolver o cuidado. Assim sendo, o sistema de referência e contrareferência compõe também esta rede de relações ao articular diversas unidades, a partir da organização dos encaminhamentos. A rede relacional aproxima os trabalhadores dos fluxos-conectivos com outras equipes e unidades de saúde, bem como têm suas conexões expandidas para o território da área da unidade ou equipe e o domicílio do usuário. ${ }^{8}$

No entanto, o sistema de saúde enfrenta problemas no que tange a sua organizacão, pois se verifica a dificuldade de integração entre seus diferentes níveis de atenção, ilustrada pela falta de referência e contra-referência, o que impede algumas possibilidades de ações e intervenções em saúde. Este fato sinaliza para a necessidade de mudanças na organização e nas práticas assistenciais dos serviços ${ }^{9-10}$, requerendo aprofundamento especial desta temática no âmbito das categorias profissionais que se configuram como elementos essenciais no sistema de referência e contra-referência.

0 desenvolvimento deste estudo baseou-se na premissa de que o sistema de referência e contra-referência configura-se como um elo entre o serviço especializado e a atenção básica. Portanto, este estudo objetivou analisar a percepção de profissionais da Estratégia de Saúde da Família acerca do sistema de referência e contra-referência de um município do interior do estado do Rio Grande do Sul.

\section{MÉTODO}

Este estudo está inserido na Linha de Pesquisa Educação, Sociedade e Integralidade na Saúde do Grupo Interdisciplinar de Pesquisa em Saúde - GIPES, do Centro Universitário Franciscano - UNIFRA. Trata-se de um estudo de cunho qualitativo, o qual se aprofunda no mundo dos significados, relações humanas, atitudes, crenças e valores, explorando uma realidade que não pode ser captada por meio de dados quantitativos. ${ }^{11}$

A pesquisa foi realizada em uma Unidade de Saúde da Família de um município localizado na região central do estado do Rio Grande do Sul, composto por uma população de cerca de 260 mil habitantes. Conta com dezesseis (16) equipes de Estratégia Saúde da Família, distribuídas em suas regiões.

Compuseram este estudo, integrantes das duas equipes vinculadas a esta unidade de saúde, sendo eles: uma (1) enfermeira, uma (1) médica, uma (1) técnica de enfermagem e seis (6) agentes comunitários de saúde, totalizando nove (9) participantes. A escolha destes profissionais foi realizada mediante um sorteio que contemplasse a representatividade de cada categoria profissional, de modo que fosse formada uma equipe 


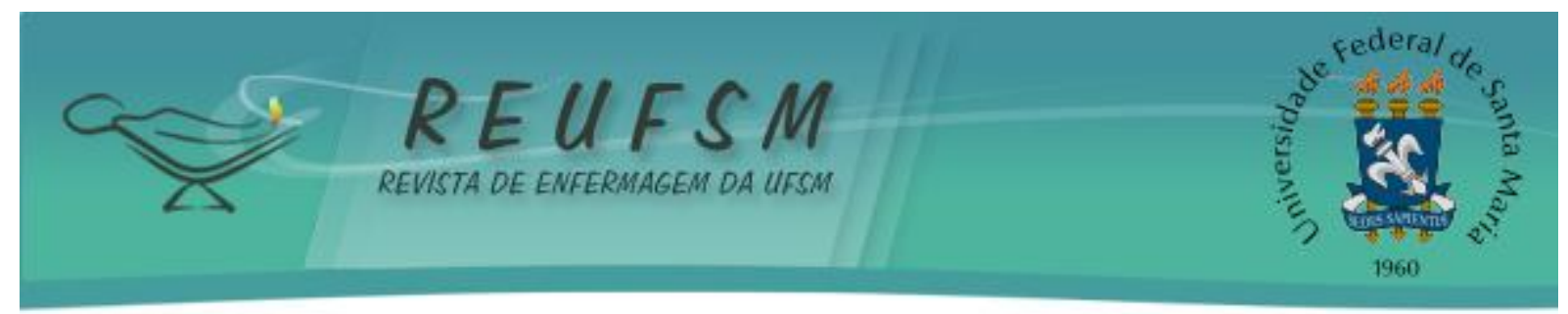

completa para o estudo, fato este que justifica a predominância da categoria profissional de agentes comunitários de saúde.

Os critérios de inclusão no estudo foram atuar nas equipes de saúde da família no período da coleta de dados e aceitar participar da pesquisa, mediante a assinatura do Termo de Consentimento Livre e Esclarecido. O período de realização da coleta de dados compreendeu os meses de agosto a novembro de 2008.

A coleta de dados foi feita por meio de entrevista semi-estruturada que contemplava questões abertas referentes ao sistema de referência e contra-referência, a Estratégia de Saúde da Família, a Atenção Básica, o acompanhamento pós-alta hospitalar e - SUS. Estas entrevistas foram gravadas em aparelho de MP3 e após transcritas para garantir dados fidedignos para análise.

Da transcrição seguiu-se o processo de análise de conteúdo temática dos dados ${ }^{12}$, na qual os mesmos foram submetidos a leituras exaustivas até se chegar à definição das unidades de significado para a construção de categorias e subcategorias, as quais nortearam toda a discussão realizada nesta pesquisa.

$\mathrm{Na}$ apresentação dos resultados, as falas ilustram os mesmos, sendo que os ACS aparecem associados a números arábicos pela ordem de realização das entrevistas, o que não ocorre com os demais profissionais tendo em vista que são únicos por categoria profissional.

Foram respeitados os preceitos éticos que constam na Resolução 196/96 do Conselho Nacional de Saúde. ${ }^{13}$ Foi elaborado um Termo de Consentimento Livre e Esclarecido, apresentado em duas vias de igual teor, ficando uma com o participante e outra com as pesquisadoras. Esta pesquisa está registrada no Comitê de Ética em Pesquisa do Centro Universitário Franciscano - UNIFRA sob o n 161.2008.2.

\section{RESULTADOS E DISCUSSÃO}

O sistema de referência e contra-referência pode ser considerado como um dos pontos importantes para viabilizar a implantação do SUS, pois, dentre outros fatores, a partir de sua estruturação, o fluxo de encaminhamento de usuários aos diversos níveis de atenção será facilitado. Para tal, destaca-se a necessidade de integração dos serviços e estabelecimento de fluxos formais de encaminhamento da clientela.

Quando questionados sobre a organização e o funcionamento do sistema de referência e contra-referência nesta unidade de saúde da família os entrevistados referem que o mesmo é inexistente no cotidiano dos serviços da realidade investigada, conforme evidenciam os depoimentos que seguem:

Não existe. Até agora a gente não consegue e é importante essa contra-referência para a gente poder ter um acompanhamento com o paciente. Se o médico nos mandasse uma contra-referência. (TÉC ENF).

O sistema de referência existe, formado no papel, mas não existe de fato. Porque tem pacientes que ficam um ano esperando a consulta e quando vão consultar já estão com outros problemas piores. A contra-referência, na realidade, não existe. Raramente, a gente recebe um bilhetinho de um especialista. Referenciar a gente referencia, agora a contra-referência é meio ilusória (MÉD).

A não estruturação deste sistema nos serviços de saúde impossibilita a continuidade da atenção à saúde, pois não há articulação entre os diferentes níveis de 


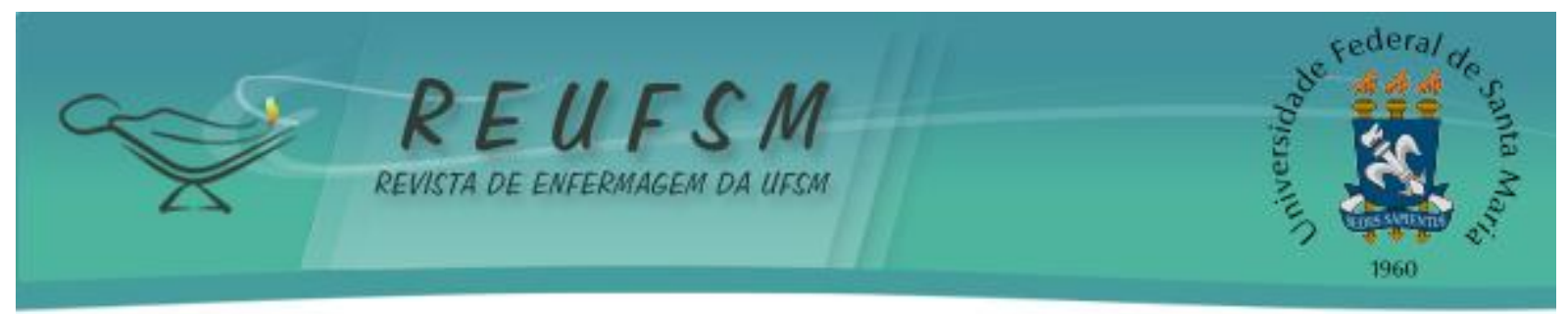

densidade tecnológica para a solução dos problemas dos usuários. Isso inclui a articulação entre profissional e equipe, entre outras equipes e o compartilhamento de informações sobre o usuário. ${ }^{14}$ Assim sendo, a falta de avaliação do funcionamento do sistema de referência e de contra-referência e de normas que o definam faz com este se organize conforme as características pessoais de cada profissional que encaminha o usuário, bem como daquele atuante nos serviços secundários e terciários, responsáveis pela contrareferência. ${ }^{15}$

Dessa forma, ressalta-se a importância desta articulação para o fortalecimento do cuidado domiciliar, o qual se configura como alternativa eficiente para prevenir, promover e restabelecer a saúde das pessoas de forma integral, pois se desenvolve em cenários peculiares, os quais exigem dos profissionais competências complexas para atender às demandas específicas da população. ${ }^{16}$

Quanto à identificação dos usuários que necessitam de cuidados, as falas dos sujeitos da pesquisa apontaram que o Agente Comunitário de Saúde (ACS) é, na maioria das vezes, quem detecta as necessidades dos usuários e as leva ao conhecimento dos demais membros da equipe de saúde. Desse modo, destacam-se alguns trechos das falas dos entrevistados que evidenciam estes argumentos:

\begin{abstract}
Minha atuação seria sobre o que o agente vem, me fala: olha, preciso de uma visita domiciliar, vamos até lá, vou ver o que houve com esse paciente, o que não houve, que medicamento está tomando (ENF).

Tem que levar todos os profissionais que for possível levar. No caso que vem do hospital, tem que ver que tipo de profissional que tu estás levando lá, se é pra fazer curativo, se é um médico. (ACS 1).
\end{abstract}

Mediante os depoimentos, considera-se que o ACS é quem, em muitas situações, elenca as necessidades de saúde dos usuários. Este fato remete a reflexões acerca dos processos de formação, capacitação e educação permanente dos ACS, especialmente por não terem formação específica no campo da saúde e necessitarem atender demandas de diversas ordens. ${ }^{1 \zeta}$ É possível que a partir da implantação do sistema de referência e contra- referência sistematizados na rotina dos serviços, esta questão seja colocada em evidência e tratada adequadamente.

Neste contexto, visualiza-se a atuação do ACS como articulador no processo de cuidar, pois são os principais elos entre as unidades básicas de saúde e suas comunidades, sendo responsáveis por facilitar o acesso a consultas, exames, medicamentos, dentre outras ações. Isto faz com que, muitas vezes, os demais membros da equipe se mobilizem para realizar as ações no interior da unidade, prestando consultas e dispensando medicamentos. $^{2}$

Algumas falas obtidas por meio das entrevistas demonstram este papel, conforme evidenciadas nos seguintes depoimentos:

Via agente comunitário, sempre é o agente que nos traz : preciso de uma visita domiciliar no paciente tal, que fez tal cirurgia (ENF). A gente identifica primeiro, se tu não ficas sabendo que aquela pessoa deu alta, está em casa, eles [os demais membros da equipe] não vão saber. Muito difícil, sempre eles esperam da gente [a informação sobre] os problemas que estão acontecendo (ACS 05). 


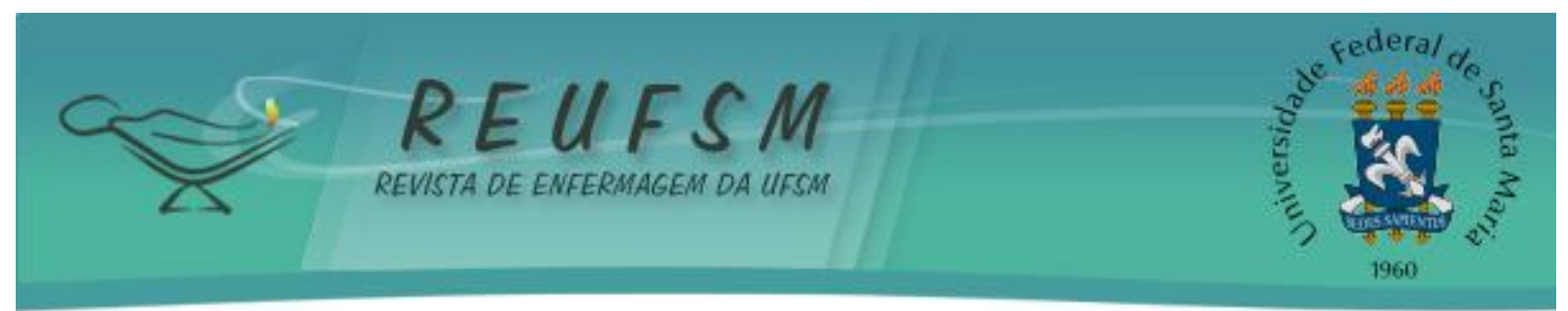

O que se vê no cotidiano dos serviços é que a resolutividade das demandas está mais ligada aos esforços dos próprios profissionais que insistem e se comprometem com a população, do que aos princípios da Atenção Básica, os quais deveriam estar arraigados nas ações de saúde, como pode ser percebido nas seguintes falas:

Às vezes tem que se virar, procurar, ou tem que ligar para alguém responsável. Mesmo tendo dificuldade, ao mesmo tempo tu superas porque tu dás um jeito (ACS 1).

Facilidade sou eu, que não espero, eu vou abrindo a porta, vamos ver que encaminhamento eu dou e vou atrás. Então eu facilito o meu trabalho, não fico parada esperando as coisas acontecerem. Se eu vejo que a coisa tem que fluir, eu dou um jeito de fluir daqui ou dali (ACS 3).

Percebe-se no cotidiano dos serviços de saúde, que o sucesso e agilidade dos encaminhamentos dependem, em grande parte, dos relacionamentos interpessoais e da informalidade, muito mais do que de um fluxo sistematizado entre os níveis de complexidade, nos quais as vias de acesso formais, muitas vezes, não funcionam adequadamente. $^{15}$

Desse modo, verifica-se que a organização da rede básica de saúde no SUS tem base em normas que estabelecem horários específicos para atender determinada clientela, que impõem fichas e senhas, e que disponibilizam ou não de certos procedimentos. Estas normatizações limitam a atuação do trabalhador ao produzir cuidado, aprisionando o seu trabalho vivo, o impedindo de estabelecer relações positivas para com os usuários. ${ }^{8}$

Assim, os trabalhadores de saúde quando desejam, operam nas suas relações outros fluxos de conexão com suas equipes, com outras unidades de saúde e com os usuários. Isto faz com que o cuidado seja produzido na nova rede que se formou e não na estrutura rígida que se alicerça na norma. ${ }^{8}$

Quando questionados sobre as dificuldades para a implementação do sistema de referência e contra-referência, os entrevistados mencionaram que a mais evidente é o déficit de recursos humanos na equipe. Esse fato complexifica a continuidade do cuidado na atenção básica, assim como o acompanhamento pós-alta hospitalar de forma mais resolutiva, como se expressam nas seguintes falas:

Temos dificuldades, porque nem tudo tu consegues resolver aqui. Porque nem sempre tu consegues alguém para fazer uma visita domiciliar, é muito difícil. Se tu consegues, leva duas ou três semanas, o paciente já resolveu o problema, daí não adianta mais. (ACS 4).

A dificuldade existe só se falta um funcionário. Como eu fiquei uns bons meses sozinha, não estava conseguindo fazer as visitas (TÉC ENF).

Os recursos humanos são pessoas que constituem o único recurso vivo e dinâmico de uma organização e são dotados de uma vocação dirigida para o crescimento e desenvolvimento. Por isso, não são insumos, componentes das instituições onde atuam, mas são peças importantes nas organizações enquanto sujeitos do processo produtivo e devem ser tratados de forma diferente dos outros recursos necessários para a atenção à saúde. ${ }^{18}$ Assim, a carência de profissionais da saúde para desempenhar as atividades dentro da ESF é um dado que dificulta a prestação da assistência em saúde com qualidade. 


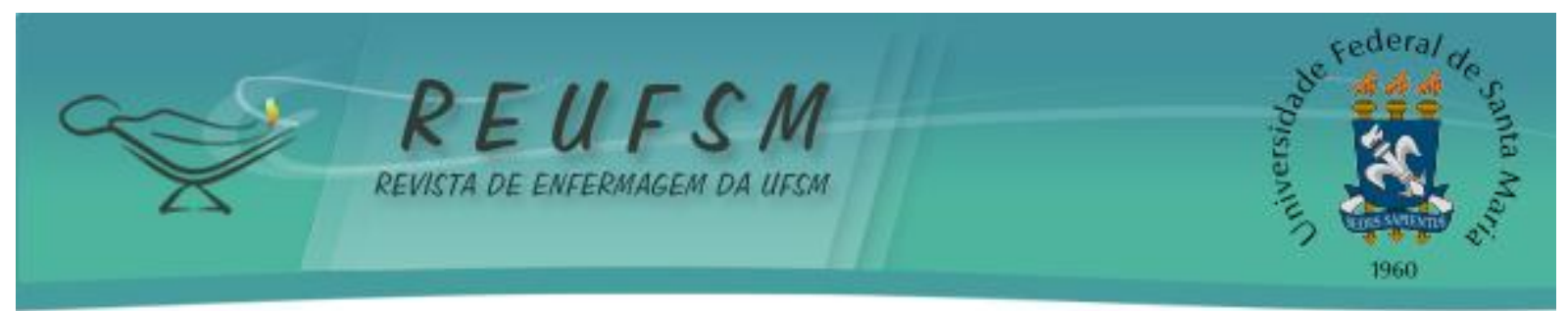

A idéia de sistemas de saúde organizados objetivando a resolução de problemas coletivos colocou em destaque as noções de rede e de elos de coesão e interdependência, unindo os diferentes atores e serviços do sistema. ${ }^{19}$ A criação de redes assistenciais na realidade pesquisada mostrou-se possuidora de lacunas, como já demonstrado pela ausência de uma sistematização do sistema de referência e contra-referência no município e também pela grande espera por atendimento nos serviços de referência, o que acarreta, em muitos casos, maiores problemas para os usuários.

Apesar destas considerações, foi possível detectar que há um engajamento dos membros da equipe da ESF estudada para fortalecer sua rede, como pode ser observado:

Agora estamos com a facilidade do matriciamento da psiquiatria, $e$ isso aí está facilitando bastante e a gente tem uma consultoria do gineco que vem de 15 em 15 dias. Então, a gente tem essas duas coisas boas. Que bom que nós tivéssemos outros colegas como um cardiologista, um endócrino, um neuro (MÉD).

Para o desenvolvimento do cuidado se faz necessário o reconhecimento de outros saberes disponíveis na equipe e de saberes e práticas disponíveis nos demais serviços de saúde. Esta constituição de redes de atenção busca a organização de linhas de cuidado, estabelecendo articulação entre equipes e fluxos de encaminhamento dos usuários conforme suas demandas e necessidades, em uma malha de cuidados progressivos e ininterruptos na qual, em cada nível articulado, se garanta acolhimento, responsabilização, resolutividade dos problemas e continuidade de atenção. ${ }^{20}$

Quando questionados acerca dos aspectos que favoreciam o processo de referência e contra-referência na unidade, os profissionais evidenciaram o papel das atividades acadêmicas na Unidade de Saúde da Família. Como foi expresso pelos depoimentos de alguns participantes da pesquisa, os acadêmicos dos cursos da área da saúde facilitam este trabalho tendo em vista que se inserem nas visitas domiciliares.

Ainda bem que a gente tem um braço, o grupo dos alunos, que cobre muitas coisas para gente, se não... (ACS 1).

Quando está o pessoal dos cursos, para nós é uma benção. Porque daí quando está só o profissional da equipe do PSF, para sair não é fácil. Daí já nos "quebra as pernas" quando os alunos não estão, para nós é muito difícil (ACS 6).

Nesta ótica, a questão da formação e do exercício profissional são fundamentais para a plena implementação de um sistema de saúde universal, formado em uma rede única, norteado pela integralidade da atenção e controle social. Além da integração ensino-serviço, a educação permanente em saúde dos profissionais atuantes é fundamental para a melhor organização e ascensão do SUS. ${ }^{21}$ Esta questão também foi abordada durante a coleta de dados:

capacitar desde a recepção, os médicos, todos nós, toda a equipe deve ser capacitada, não uma vez lá e outra cá, mas ter capacitações seguidas para lidar com as pessoas dentro de todas as áreas (ACS 4).

Neste percurso, tem-se a educação permanente como estratégia fundamental para as transformações do trabalho no setor, para que venha a ser lugar de atuação 


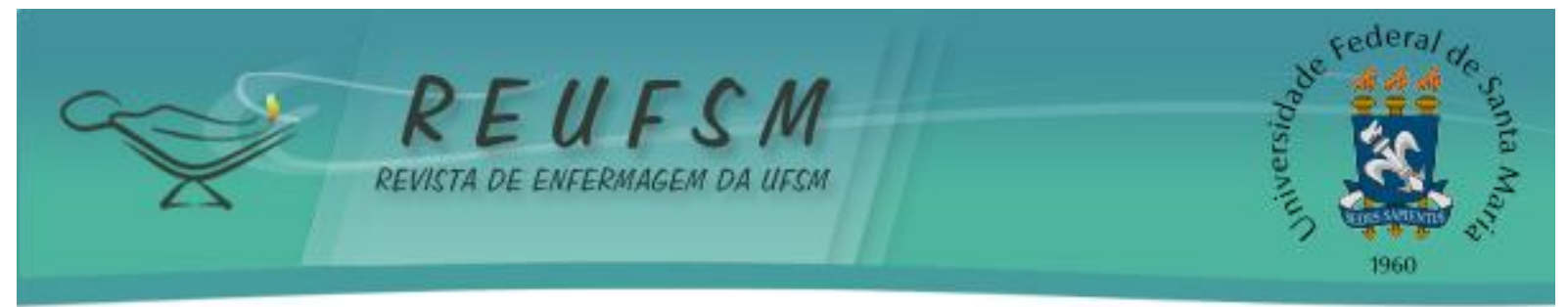

crítica, reflexiva, propositiva, compromissada e competente. 0 trabalho em saúde é um trabalho de escuta, em que a interação entre profissional de saúde e usuário é determinante da qualidade da resposta assistencial. Ressalta-se que a área da saúde é um espaço onde os processos de educação permanente se configuram como uma necessidade constante. ${ }^{22}$

Além disso, um dos desafios que se coloca para os cursos que formam trabalhadores de saúde consiste em superar as práticas educativas em saúde desenvolvidas com o único objetivo de modificar comportamentos individuais, eliminando ou promovendo determinados hábitos de vida e restritas a estratégias pontuais que tem se mostrado ineficientes para produzir as transformações esperadas. Assim, um ponto a ser fortalecido é o foco na formação de profissionais capazes de compartilhar saberes e decisões, num processo de ampliação e potencialização da sua capacidade crítica e de intervenção na realidade, fatores essenciais para a sistematização e efetivação dos processos de referência e contra-referência.$^{23}$

Para isto, os novos profissionais de saúde devem ter suas visões focadas no indivíduo como um todo, inserido em uma sociedade, em um meio ambiente, como ser possuidor de cultura, e não visualizar somente um corpo segmentado em sistemas, como se fossem peças de uma máquina.

\section{ALGUMAS CONSIDERAÇÕES}

A partir das discussões proporcionadas pela pesquisa, é possível concluir que muito há que se evoluir no que tange a organização dos serviços de saúde. Os achados da pesquisa permitem analisar o sistema de saúde como um sistema possuidor de lacunas no que tange à comunicação que deveria existir, efetivamente, entre os profissionais que atuam em diferentes níveis de atenção, uma vez que cada um desenvolve seu trabalho separadamente, deixando os usuários a mercê de um sistema de saúde ineficiente.

A estruturação do sistema de referência e contra-referência ainda não está consolidada na realidade investigada, pois há demora no processo de referência e a contrareferência não é vista. Frente a isto, têm-se a necessidade de pensar a continuidade do cuidado ao usuário na comunidade de forma mais comprometida, onde este processo não se limite a atuação de cada profissional da equipe, que de forma individual, busca a resolutividade das demandas. Os serviços devem organizar-se de maneira que não seja somente o agente comunitário de saúde quem realiza a contra-referência, uma vez que esta atuação necessita perpassar o fazer de todos os integrantes da equipe de saúde a fim de que seja beneficiada pela qualificação e fazer profissional de cada um dos atores envolvidos.

O déficit quantitativo de profissionais para atuar neste serviço também foi apontado como fator que retarda a efetivação do sistema de referência e contrareferência. Por outro lado, a atuação dos acadêmicos da área da saúde no serviço parece amenizar o impacto deste déficit, sendo fortalecida a concepção de que a integração ensino-serviço é de grande valia. Contudo, na lógica da organização dos serviços, o vínculo e a assistência não devem ficar a cargo dos acadêmicos, pois estes estão em processo de formação e têm atuação temporária junto às organizações de saúde.

Considera-se, portanto, a necessidade de uma reorganização dos serviços de saúde, uma vez que os fundamentos do Sistema Único de Saúde parecem ainda não terem sido incorporados na organização do sistema e, consequentemente, no fazer dos profissionais que atuam neste contexto. 


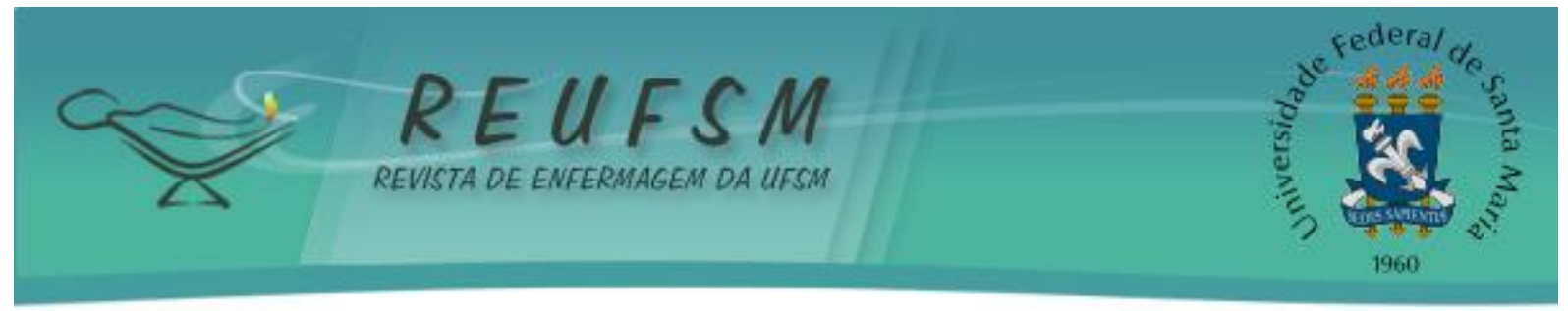

\section{REFERÊNCIAS}

1. Ministério da Saúde (BR). Sistema de planejamento do SUS: uma construção coletiva: instrumentos básicos. Série Cadernos de Planejamento. $2^{\mathrm{a}}$ ed. Brasília (DF): Ministério da Saúde; 2006. 46p.

2. Sousa MF. O Programa Saúde da Família no Brasil: análise do acesso à atenção básica. Rev Bras Enferm. 2008; 61(2):153-58.

3. Carvalho BG, Martin GB, Cordoni Jr L. A Organização do Sistema de Saúde no Brasil. In: Andrade SM, Soares DA, Cordoni Jr L (org). Bases da Saúde Coletiva. Londrina: Ed. UEL; 2001.p.27-59.

4. Ministério da Saúde (BR). Anais da $8^{\mathrm{a}}$ Conferência Nacional de Saúde. Anais da $8^{\mathrm{a}}$ Conferência Nacional de Saúde, 1986 mar 17-21. Brasília: Centro de Documentação do Ministério da Saúde;1986. p.430.

5. Brasil. Senado Federal. Constituição da República Federativa do Brasil, de 5 de outubro de 1988. Diário Oficial da União, Brasília; 1988.

6. Ministério da Saúde (BR). Legislação Básica do Sistema Único de Saúde (SUS) [Internet]. Brasília: Ministério da Saúde; 2009 [acesso em 2009 jun 14]. Disponível em: http://portal.saude.gov.br/saude.

7. Ministério da Saúde (BR). Departamento de Atenção Básica [Internet]. Brasília (DF): Ministério da Saúde; 2007 [acesso em 2008 abr 28]. Disponível em: http://www.saude.gov.br

8. Franco TB. As redes na micropolítica do processo de trabalho em saúde. In: Pinheiro R, Mattos RA (org). Gestão em redes: práticas de avaliação, formação e participação na saúde. Rio de Janeiro: CEPESC-IMS-UERJ/ABRASCO; 2006. p.459-74.

9. Vasconcelos CM, Pasche DF. O Sistema Único de Saúde. In: CAMPOS GWS. Tratado de Saúde Coletiva. São Paulo-Rio de Janeiro: Hucitec; 2006.

10. Santos AS, Miranda SMRC. A enfermagem na gestão em atenção primária à saúde. São Paulo: Manole; 2007.

11. Minayo MCS. Pesquisa social: teoria, método e criatividade. $18^{\mathrm{a}}$ ed. Petrópolis: Vozes; 2001.

12. Minayo MCS. O desafio do conhecimento: pesquisa qualitativa em saúde. $3^{\mathrm{a}}$ ed. São Paulo: Hucitec-Abrasco; 1994.

13. Ministério da Saúde (BR). Conselho Nacional de Saúde. Comitê Nacional de Ética em Pesquisa em Seres Humanos. Resolução 196, de 10 de outubro de 1996 diretrizes e normas regulamentadoras de pesquisa envolvendo seres humanos. Brasília (DF); 1997.

14. Silva JAG, Carvalho LC, Silva VMN, Alves MGM, Mascarenhas MTM. Avaliação de redes de atenção à saúde: contribuições da integralidade. In: Pinheiro R, Mattos RA (org). Gestão em Redes: Práticas de avaliação, formação e participação na saúde. Rio de Janeiro: CEPESC; 2006.p.61-87.

15. Juliani CMCM, Ciampone MHT. Organização do sistema de referência e contrareferência no contexto do sistema único de saúde: a percepção de enfermeiros. Rev Esc Enferm USP. 1999; 33(4):323-33. 


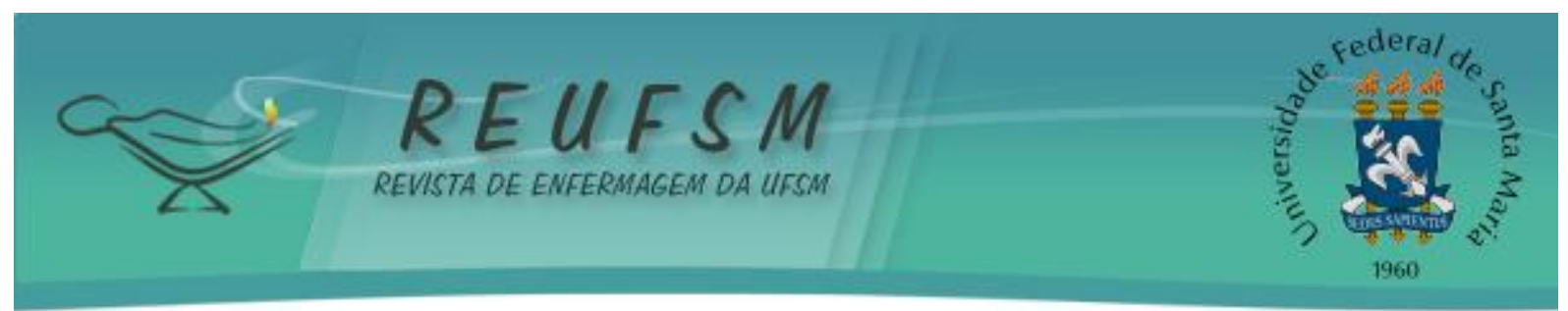

16. Catafesta F, Gomes IM, Correa ABH, Lacerda MR. Nurses experience on home care competence development: Grounded Theory. Online Braz J of Nurs [periódico na internet]. 2009 [acesso em $2010 \mathrm{Apr}$ 16]; 8(3):[aproximadamente 14 páginas]. Available from: http://www.objnursing.uff.br/index.php/nursing/issue/view/21

17. Sousa MF. Capital Humano no PSF: revendo o passado e imaginando o futuro. São Paulo: Hucitec; 2002.p.105-14.

18. Sakai MH, Nunes EFPA, Martins VL, Almeida MJ, Baduy RS. Recursos Humanos em Saúde. In: Andrade SM, Soares DA, Cordoni Jr L (org). Bases da Saúde Coletiva. Londrina: UEL; 2001.p.111-24.

19. Viana ALDA, Faria R, Pacífico H. O SUS e as novas práticas de avaliação para gestão em redes: é possível conciliar a visão clássica de avaliação com novas práticas. In: Pinheiro R, Mattos RA (org). Gestão em Redes: Práticas de avaliação, formação e participação na saúde. Rio de Janeiro: CEPESC; 2006.p.135-49.

20. Silva JAG, Pontes ALM, Henriques RLM. O cuidado como categoria analítica no ensino baseado na Integralidade. In: Pinheiro R, Ceccim RB, Mattos RA (org). Ensinar Saúde: a Integralidade e o SUS nos cursos de graduação na área da saúde. Rio de Janeiro: IMS/ UERJ: CEPESQ: ABRASCO; 2005. p.93-110.

21. Pontes ALM, Silva JAG, Pinheiro R. Ensino da saúde e a rede de cuidados nas experiências de ensino-aprendizagem. In: Pinheiro R, Ceccim RB, Mattos RA (org). Ensinar Saúde: a Integralidade e o SUS nos cursos de graduação na área da saúde. Rio de Janeiro: IMS/ UERJ: CEPESQ: ABRASCO; 2005. p.251-74.

22. Ceccim RB, Feuerwerker LCM. O Quadrilátero da Formação para a Área da Saúde: Ensino, Gestão, Atenção e Controle Social. Rev Saude Colet. 2004;14(1):41-65.

23 Colomé JS, Oliveira DLLC. A educação em saúde na perspectiva de graduandos de Enfermagem. Rev Gauch Enferm. 2008;29(3):347-53.

Data de recebimento: 07/12/2010

Data de aceite: 14/01/2011

Contato com autora responsável: Juliana Silveira Colomé

E-mail: julianacolome@yahoo.com.br 